\title{
CARACTERIZAÇÃO DOS ESTÁGIOS FENOLÓGICOS EM SETE CULTIVARES E SELEÇÕES DE NOGUEIRA-MACADÂMIA ${ }^{1}$
}

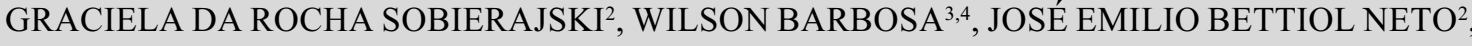 \\ EDVAN ALVES CHAGAS ${ }^{2}$, FERNANDO ANTONIO CAMPO-DALL'ORTO ${ }^{2,4}$
}

RESUMO - O conhecimento dos estádios florais e do desenvolvimento das nozes da nogueira-macadâmia é indispensável para o adequado manejo das plantas, visando a pesquisas de polinização e de cruzamentos controlados. Pesquisaram-se, neste trabalho, os padrões fenológicos temporais de sete cultivares de macadâmia (Macadamia integrifolia), do banco de germoplasma do Instituto Agronômico (IAC). Verificaram-se pequenas variações entre os estágios fenológicos iniciais, desde a emissão dos rácemos até a fase de botão floral inchado. O ciclo desde a emissão do botão floral até a queda dos frutos foi de 253 dias. Os estágios fenológicos - frutos maduros e queda dos frutos - ocorreram a partir do dia 10 de fevereiro até o final de março.

Termos para indexação: Macadamia integrifolia, macadâmia, seleções IAC, fenologia.

\section{CHARACTERIZATION OF THE PHENOLOGICAL STAGES OF SEVEN MACADAMIA NUT CULTIVARS AND SELECTION}

\begin{abstract}
The knowledge of phenological stages and nut development of macadamia trees is essential for the adequate management of the plant, aiming pollination studies and controlled crossing between cultivars, needed in breeding programs. The phenological temporal patterns of seven macadamia cultivars selected at the Instituto Agronômico (IAC) were researched in the collection of cultivars. Small variations were verified among the initial phenological stages, from emission of the racemes up to the swollen flower bud stage. The complete cycle, from the flower bud emission to the fruit dropping took 253 days. The phenological stages - mature fruits and fruit dropping - occurred from the second tenth of February to the end of March.
\end{abstract}

Index Terms: Macadamia integrifolia, macadamia nut, phenology, IAC selections.

A macadâmia é uma nogueira originária das florestas tropicais australianas, sendo hoje cultivada em diversos países, a exemplo do Brasil e Estados Unidos. Por ser de procedência tropical, a macadâmia desenvolve-se muito bem nos dos Estados de São Paulo, Espírito Santo, Bahia e Rio de Janeiro, sendo esses responsáveis por $92 \%$ da produção nacional, estimada em 3.200 toneladas de "noz em casca" (Sobierajski et al., 2005). Embora tenha sido introduzida no Brasil na década de 40, muitos dos tratos culturais empregados são adaptações de pesquisas desenvolvidas em outros países, como Austrália e Estados Unidos, em condições edafoclimáticas diferentes (Sacramento \& Pereira, 2003). Nas condições climáticas do Havaí (EUA), o período de florescimento ocorre entre novembro e maio, com picos de floração entre janeiro e março (Nagao et al., 1988). Na Austrália, a floração inicia-se em maio (Moncur et al., 1985; citado por Sacramento \& Pereira, 2003). Boyton \& Hardner (2002) relatam que é em final de agosto, o período em que as flores se apresentam abertas. No Brasil, pesquisas mostraram que o intumescimento das gemas florais ocorre em maio, com pico de floração em junho (Sacramento \& Pereira, 2003).

O conhecimento da biologia floral e do desenvolvimento das nozes é indispensável para o adequado manejo das plantas e para pesquisas de polinização e de cruzamentos controlados. Além disso, a caracterização fenológica das cultivares de macadâmia fornece subsídios importantes para aumento de produtividade $\mathrm{e}$ qualidade das amêndoas, visto que a parcial autoincompatibilidade (Sacramento et al., 1999) pode ser evitada com o plantio intercalar de cultivares.

Diante do exposto, objetivou-se descrever os ciclos fenológicos de sete cultivares de macadâmia, nas condições edafoclimáticas de Jundiaí, São Paulo. Para descrever o padrão fenológico, utilizaram-se sete acessos do banco de germoplasma do Centro APTA Frutas/IAC, situado em Jundiaí-SP (23 ${ }^{\circ}$ 'S; $46^{\circ} 55^{\prime} \mathrm{W}$; altitude 700 metros): 'Keaudo' (IAC 2-23), 'Keaumi' (IAC 4-20), 'Kakedo' (IAC 4-10), 'Keauhou' (HAES 246), 'Nuuanu' (HAES 336), IAC 4-8 e IAC 11-8.

As avaliações iniciaram-se em julho de 2005 , quando as gemas florais se apresentavam intumescidas, estendendo-se até a queda natural dos frutos, em março de 2006. As observações foram realizadas em sete cultivares, variando entre cinco e três plantas por cultivar, representando os tratamentos, e em 10 setores da copa (interior e borda), representando as repetições. A caracterização dos períodos de florescimento e de frutificação foi baseada em avaliações semanais, utilizando-se da classificação

'(Trabalho 199-06). Recebido em : 29-11-2006. Aceito para publicação em : 26-07-2007.

${ }^{2}$ Pesquisador Científico; Centro de Fruticultura/Instituto Agronômico (IAC) E-mail: sobierajski@iac.sp.gov.br

${ }^{3}$ Pesquisador Científico; Centro Experimental Central/Instituto Agronômico (IAC)

${ }^{4} \mathrm{Com}$ bolsa de produtividade em pesquisa do CNPq. 
fenológica apresentada na Figura 1, agrupando-se 12 estádios:

1 - gemas intumescidas, primeiros indícios de diferenciação das gemas florais;

2 - crescimento do racemo, período em que houve a elongação do racemo floral;

3 - formação dos botões florais;

4 - flores em pré-antese;

5 - flores abertas, liberação do pólen;

6 - flores senescentes, após liberação do pólen;

7 - flores fecundadas;

8 - frutificação efetiva, início do crescimento dos frutos;

9 - crescimento dos frutos;

10 - final do período de crescimento dos frutos; carpelo;

11 - frutos maduros, alteração de coloração e abertura do

12 - queda natural dos frutos.

Para homogeneizar as avaliações, foram demarcados pontos em que a gema floral possuía $2 \mathrm{~mm}$ de comprimento (Estágio 1). Os demais estágios foram caracterizados quando $50 \%$ ou mais das flores ou frutos de um racemo se encontravam nas respectivas fases determinadas na Figura 1. Para testar a significância das diferenças entre cultivares, ocorridas nas diversas fases do estudo, utilizou-se o programa estatístico SAS (SAS, 2000) e requerido o procedimento GLM para a comparação das médias das cultivares.

Pelas observações realizadas, constatou-se que o intumescimento das gemas florais se iniciou em maio, com pico em meados de junho. Verificou-se que o início do intumescimento das gemas coincidiu com a queda de temperatura (abril temperatura média: $17,07^{\circ} \mathrm{C}$; maio - temperatura média: $13,75^{\circ} \mathrm{C}$ ). Sacramento \& Pereira (2003), ao pesquisar as seleções IAC 5-10 e IAC 8-17, concluíram que o período de intumescimento das gemas florais ocorria a partir de meados de maio, com maior intensidade a partir do início de junho. Os mesmo autores também verificaram a ocorrência de queda da temperatura no início da diferenciação das gemas.

Verificaram-se pequenas variações entre cultivares nos estágios fenológicos iniciais, desde o crescimento dos racemos até a fase de botão floral inchado, porém essas não foram significativas pelo teste Tukey $(\mathrm{P}<0,05)$. Na média das observações, todas as cultivares apresentaram concomitância de racemos com $100 \%$ de flores abertas na terceira semana de setembro. Esses dados são concordantes com aqueles obtidos por Sacramento \& Pereira (2003), nas condições de Jaboticabal
(SP), em que o período com maior concentração de flores em antese se situou entre meados de agosto até meados de setembro. Esses autores constataram que não houve diferenças significativas entre as fases de crescimento da inflorescência até a antese, entre cultivares, havendo, no entanto, diferenças significativas entre os anos observados.

Os eventos reprodutivos, florescimento e frutificação, apresentaram desenvolvimento do tipo sigmoidal duplo (Figura 2), com duração média de 5 e 18 semanas, respectivamente. Sacramento \& Pereira (2003), analisando o crescimento da inflorescência e da flor + pedicelo, encontraram o mesmo padrão de desenvolvimento. Moncur et al. (1985), citados por Sacramento \& Pereira (2003), relatam que a fase de alongamento do racemo apresenta um crescimento do tipo exponencial linear. Apesar das pequenas diferenças ocorridas durante o crescimento do racemo e a formação do botão floral, na média das observações, todas as cultivares apresentaram concomitância de racemos com flores abertas após nove semanas de observações. Na Austrália, a fase "flor aberta" inicia-se no final de agosto e, devido a variações genéticas, esse período estende-se por 33 dias (Boyton \& Hardner, 2002).

A maturação dos frutos ocorreu a partir da segunda dezena de fevereiro e a queda dos frutos a partir da segunda quinzena de março até o final do mesmo mês. Todas as cultivares pesquisadas apresentaram frutos deiscentes. Ressalta-se que houve a observação de um grande número de racemos sem formação de frutos ou com baixo pegamento de nozes. O ciclo completo, desde a emissão da gema floral até a queda dos frutos, foi de 253 dias, para todas as cultivares.

Assim, concluímos que: o intumescimento das gemas florais inicia-se em maio, coincidindo com a queda da temperatura; não há sincronismo nos estágios fenológicos numa mesma árvore; a plena floração das cultivares ocorreu na terceira semana de setembro, e o ciclo desde a emissão dos racemos até a queda das nozes é de 253 dias. 


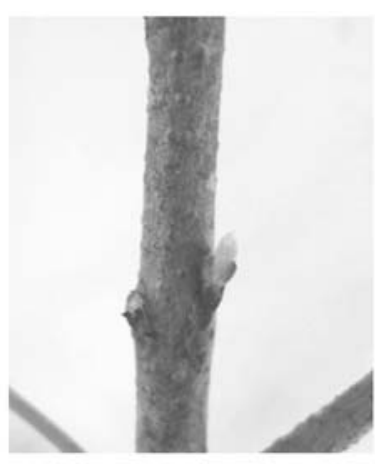

1

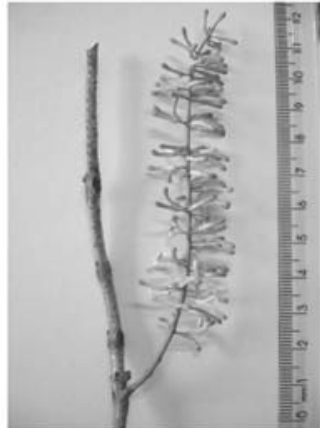

4

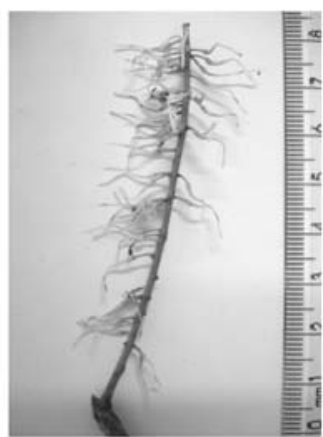

7

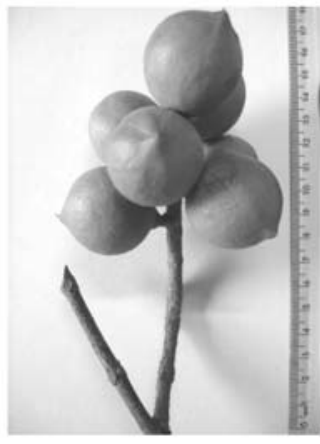

10

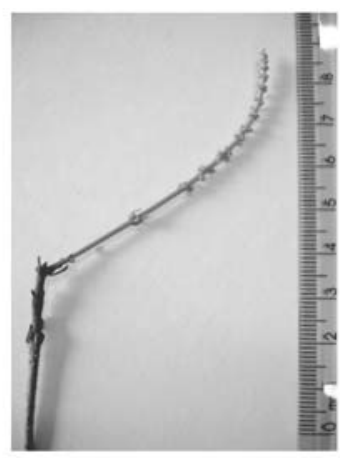

2

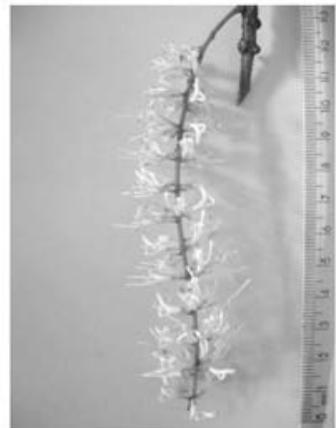

5

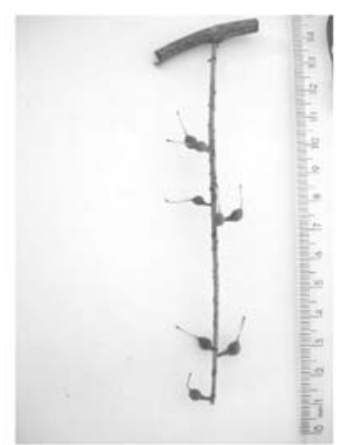

8

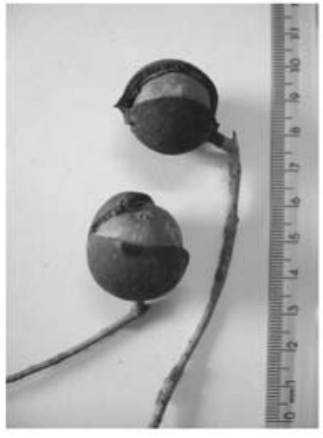

11

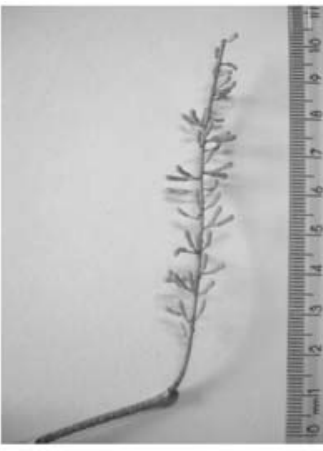

3

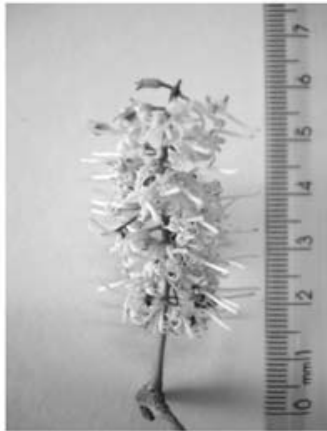

6

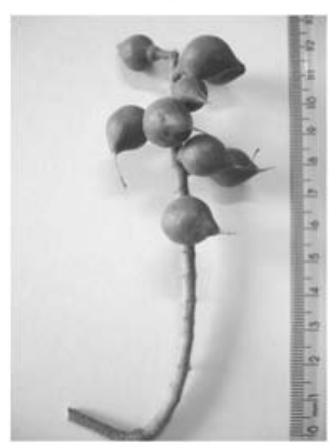

9

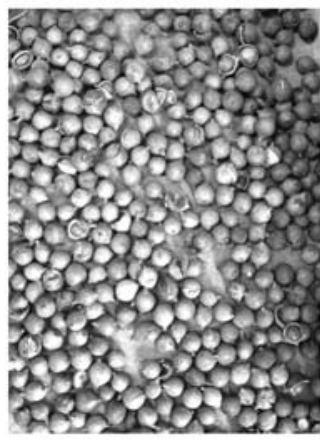

12

FIGURA 1- Escala fenológica da macadâmia: 1. gemas intumescidas; 2. crescimento do racemo; 3 . formação dos botões florais; 4. flores em pré-antese; 5. flores abertas; 6. flores senescentes; 7. flores fecundadas; 8. frutos formados; 9. crescimento do fruto; 10. final do período de crescimento dos frutos; 11. frutos maduros, e 12. queda dos frutos. 


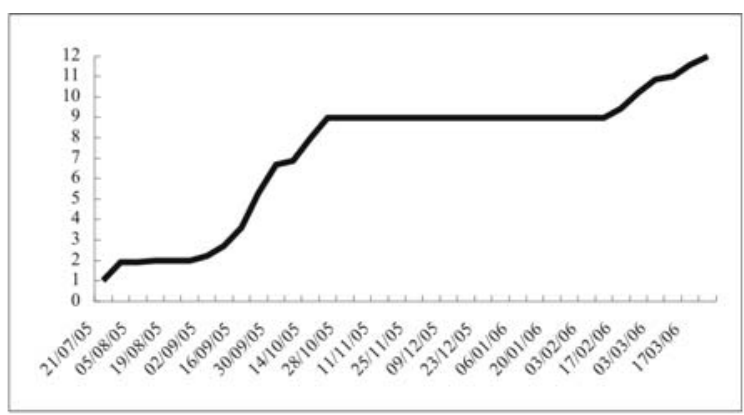

IAC 2-23 "Keaudo"

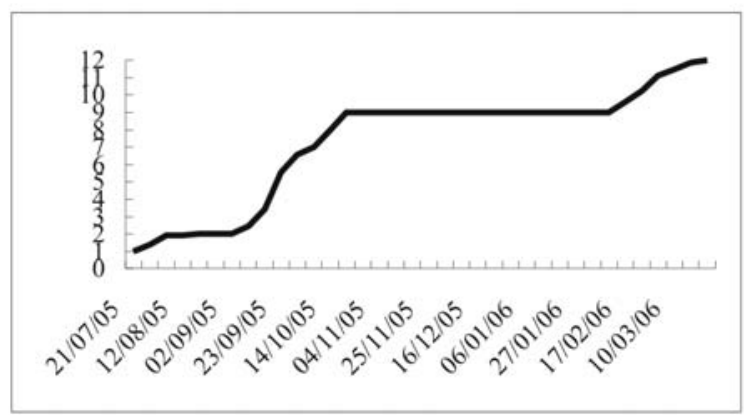

IAC 9-20

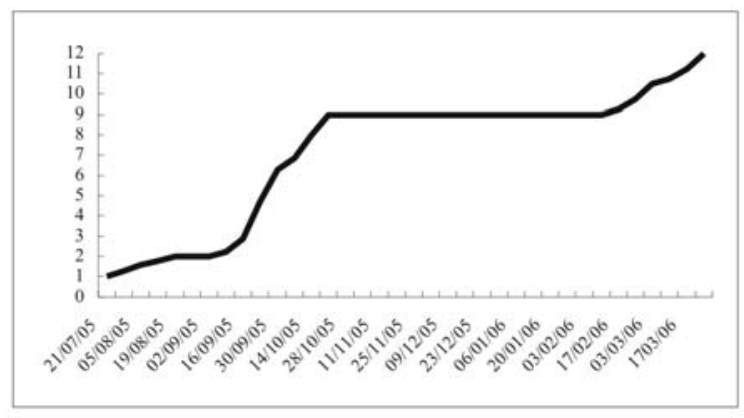

IAC 4-10 "Kakedo"

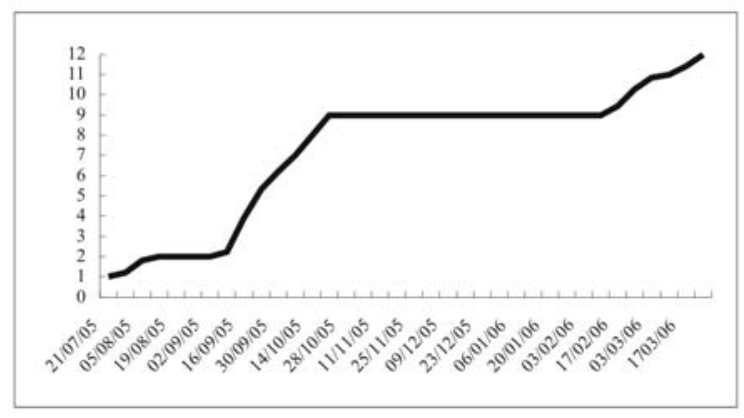

IAC 11-8

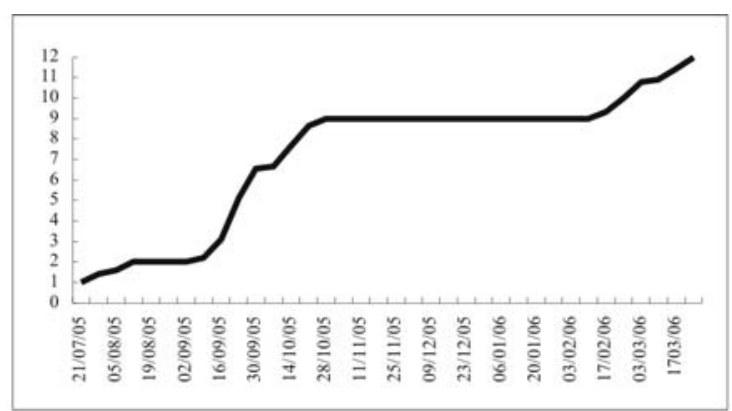

IAC 4-20 "Keaumi"

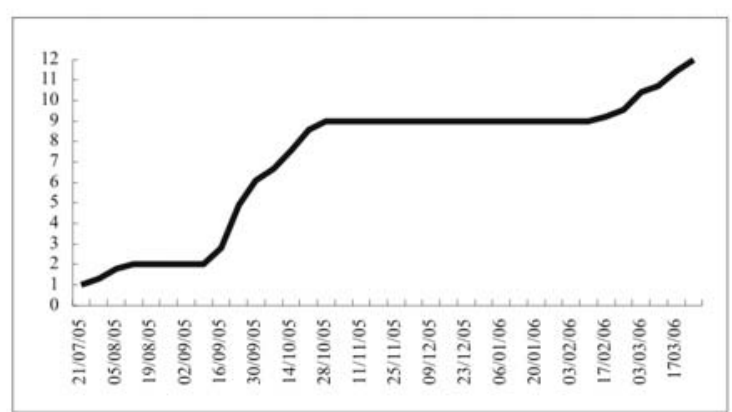

HAES 336 "Nuuanu"

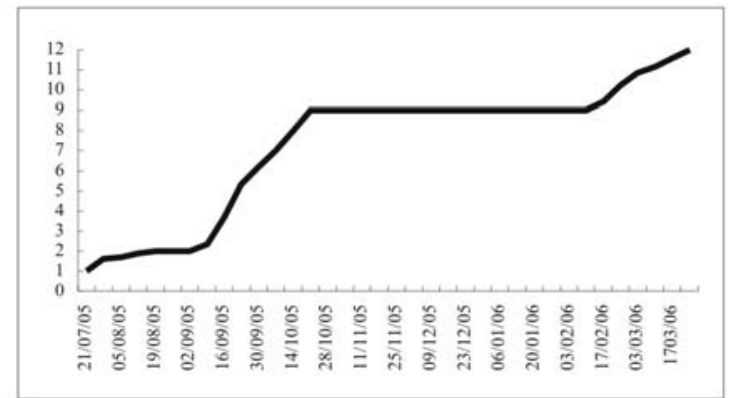

IAC 4-8

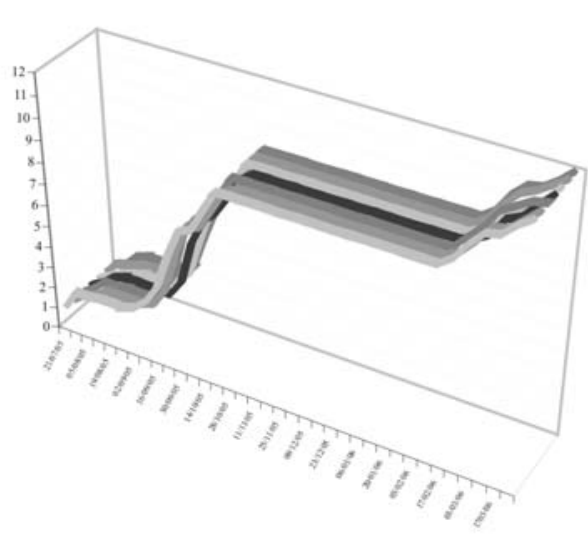

Conjunto das sete cultivares

FIGURA 2- Evolução da fenologia de sete cultivares de nogueira-macadâmia, ciclo 2005-2006. 


\section{REFERÊNCIAS}

BOYTON, S.J.; HARDNER, C.M. Phenology of flowering and nut production in macadamia. Acta Horticulturae, Wageningen, n.575, p.381-387, 2002

NAGAO, M.A.; KOBAYASHI, K.D.; SAKAI, W.S. Flowering, nut set and premature nut drop of macadamia. In.: ANNUAL PROCCEDINGS, 28., 1988, Hilo: Hawaii Macadâmia Nut, 1988. p.54.

SACRAMENTO, C.K.; PEREIRA, F.M.; PERECIN, D.; SABINO, J.C. Capacidade combinatória para frutificação em cultivares de nogueira-macadâmia. Pesquisa Agropecuária Brasileira, Brasília, v.34, n.11, p. 2045-2049, 1999.
SACRAMENTO, C.K.; PEREIRA, F.M. Fenologia da floração da nogueira-macadâmia (Macadamia integrifolia Maiden \& Betche) nas condições climáticas de Jaboticabal, São Paulo, Brasil. Revista Brasileira de Fruticultura, Jaboticabal, v.25, n.1, p.19-22, 2003.

SAS INSTITUTE INC. SAS procedures guide: version 8 (TSMO) 2000. Disponível em: <www.sas.com>. Acesso em: 19 jan. 2006

SOBIERAJSKI, G.R.; FRANCISCO, V.L.F.S.; ROCHA, P.; GHILARDI, A.A.; MAIA, M.L. Noz-macadâmia: produção, mercado e situação no Estado de São Paulo. Informações Econômicas, São Paulo, v.36, n.5, p.25-36, 2005. 